Arendt, J. C. - Contribuições alemãs para o estudo das literaturas regionais

\title{
Contribuições alemãs para o estudo das literaturas regionais
}

\author{
German contributions to the study of regional literatures
}

João Claudio Arendt ${ }^{1}$

\begin{abstract}
This paper approaches questions concerning categories such as regional and universal and the exhaustion of the latter as qualifying criterion applied to regional literature works. On the other hand, there are theoretical and methodological contributions developed in the German academic field (Scheichel 1993; Stüben 2002; Grywatsch 2008), where the regional literature finds a favoured space in the discussions, and the criteria for measuring the works quality are built relying on sociological aspects of production and reception into regional and supraregional contexts.
\end{abstract}

Keywords: Regionality; regional and supra-regional literature; reception and mediations.

Resumo: Neste artigo, abordam-se questões pertinentes às categorias do regional e do universal e ao consequente esvaziamento desta última como critério de qualificação de obras literárias regionais. Na contrapartida, trazem-se contribuições teóricas e metodológicas desenvolvidas no meio acadêmico alemão (SCHEICHEL 1993; STÜBEN 2002; GRYWATSCH 2008), onde a literatura regional encontra um espaço privilegiado nos debates, e os critérios de mensuração da qualidade das obras são construídos com base em aspectos sociológicos de produção e recepção dentro dos âmbitos regional e suprarregional.

Palavras-chave: Regionalidade; literatura regional e suprarregional; recepção e mediações.

\footnotetext{
${ }^{1}$ Doutor em Letras pela PUCRS. Professor no Programa de Mestrado em Letras, Cultura e Regionalidade da Universidade de Caxias do Sul - PPGLET/UCS. Diretor da revista eletrônica Antares (Letras e Humanidades). Bolsista CAPES para Estágio Pós-doutoral na Freie Universität Berlin. Email: jcarendt@ucs.br
} 
Arendt, J. C. - Contribuições alemãs para o estudo das literaturas regionais

\section{Introdução}

Nos estudos literários brasileiros, o termo universal aparece quase com a mesma frequência que a palavra regional. Esta última, enquanto epíteto para uma literatura de ambientação não necessariamente rural, mas circunscrita por uma determinada região, encontraria naquele (e somente nele!) seu impulso para transpor as fronteiras da região e gozar a medida maior da excelência artística. Basta que alguém mencione uma obra regionalista canônica para que em seguida se veja ressalvado um admirável universalismo atingido por meio de artifícios estéticos de complexa aferição. É comum que se afirme que, apesar do uso de um dialeto de circulação restrita, da ambientação rural e da presença de tipos humanos regionais ${ }^{2}$, tal ou qual obra consegue transpor os limites da região e atingir o status universal. O regional parece sofrer, assim, de um irreparável demérito de origem, diminuído pela pecha da estreiteza, da menoridade, do provincianismo, de modo que seu ingresso no universal seria assegurado apenas com a ressalva do belo e do sublime.

Aliás, a afirmação de MACHADO DE ASSIS, na remota data de 1873, de que "não é menos certo que tudo é matéria de poesia, uma vez que traga as condições do belo ou os elementos de que ele se compõe" (1942: 136), ou de "que não está na vida indiana todo o patrimônio da literatura brasileira, mas apenas um legado, tão brasileiro quanto universal" (1942: 136), parece ainda ser a tônica dos atuais estudos sobre a literatura regional. A falta de revisão teórica e crítica permitiu a consolidação desses parâmetros, o do belo e o da universalidade, e seu uso na avaliação das produções literárias regionais do Brasil. De imediato, dois exemplos podem ilustrar essa questão, sem que por ora se façam maiores digressões sobre elas: o primeiro, de Antonio CANDIDO, por ocasião do lançamento de Sagarana, de Guimarães Rosa, em 1946: "Sagarana nasceu universal pelo alcance e pela coesão da fatura"; o segundo, de autoria de Alfredo BosI, em 1970, refere-se a Graciliano Ramos: "Daí parecer precária, se não falsa, a nota de regionalismo que se costuma dar a obras em tudo universais como São Bernardo e Vidas secas" (Bosi 2004: 402).

\footnotetext{
${ }^{2}$ Ver, neste caso, a explanação teórica e a análise crítica efetuadas por Afrânio Coutinho, no capítulo "O regionalismo na ficção", que integra o volume IV de A literatura no Brasil.
} 
Arendt, J. C. - Contribuições alemãs para o estudo das literaturas regionais

Na opinião de Ligia CHIAPPINI, é compreensível o esforço dos críticos para excluir da tendência regionalista os chamados "grandes autores", e o argumento utilizado nesse sentido é o de que "a qualidade literária de suas obras os elevaria do regional ao universal". Todavia, a crítica negligenciaria o fato de que é o "espaço histórico-geográfico, entranhado e vivenciado pela consciência das personagens, que permite concretizar o universal" (CHIAPPINI 1995: 157). Desse modo, consoante a autora, dever-se-ia não distinguir os tipos de regionalismo existentes, mas fazer a distinção estética entre obras boas e más, tendo como foco o efeito que elas podem ter sobre os leitores.

Apesar disso, a discussão acerca do significado das categorias região, regionalismo, regionalidade e literatura regional avançou em proporção menor que as abordagens dedicadas à emissão de juízos de valor. A maioria dos estudos nessa perspectiva parece ainda se preocupar essencialmente com o conceito de regionalismo e toma a noção de região de forma apriorística, geralmente oriunda da geografia tradicional: ou seja, antes como espaço físico, delimitado por fronteiras naturais, do que como espaço histórica e culturalmente construído por diferentes formas de representação.

Em razão do enfoque pretendido neste ensaio, não se objetiva aqui, em hipótese alguma, sobrepujar a tradição crítica latino-americana sobre o regional(ismo). Como sugere o título do trabalho, pretende-se debater aspectos conceituais e metodológicos referentes ao regionalismo literário e à literatura regional, apresentando uma série de obras recentes da produção acadêmica alemã sobre o tema, para assim possibilitar sua eventual incorporação às discussões e pesquisas no Brasil. $^{3}$

\footnotetext{
3 A propósito do tema, ver também JOACHIMSTHALER, Jürgen. "A literarização da região e a regionalização da sua literatura", traduzido do original em alemão e publicado em Antares (Letras e Humanidades), Caxias do Sul, ano 1, nº2, jul./dez. 2009 . http://www.ucs.br/ucs/tplRevistaLetras/posgraduacao/strictosensu/letras/revista/2/sumario/literalizacao.pdf
} 
Arendt, J. C. - Contribuições alemãs para o estudo das literaturas regionais

\section{2. $\bigcirc$ transbordo (Austritt) da literatura regional}

Sigurd Paul Scheichl, da Universidade de Innsbruck ${ }^{4}$ - ao mencionar a história editorial do grupo de poetas Jung-Wien que, por volta de 1900, mesmo localizado na capital austríaca, optou por divulgar sua produção através da editora berlinense S. Fischer, bem como discutir exemplos oriundos da literatura de Siebenbürgen e do Tirol -, apresenta aspectos interessantes sobre o tema, a começar pela definição de literatura regional, tomada de Norbert Mecklenburg (1982): "Entendo como literatura regional aquela literatura limitada do ponto de vista da difusão e prestígio, a qual, porém, não se restringe necessariamente a temas regionalistas" (SCHEICHL 1993: 34). ${ }^{\mathbf{5}}$

Com o intuito de recortar melhor seu estudo, Scheichl propõe duas questões centrais: 1) Quem pertence de fato apenas à literatura regional? 2) Quem se enquadra no âmbito suprarregional da literatura de língua alemã e pode ser aí inserido por suas maiores ou menores relações regionais? Ao mesmo tempo, o autor relativiza esse tipo de classificação por crer que existem autores que desejam atuar somente no limitado âmbito regional e outros autores que renunciam aos temas regionais. Além disso, o critério qualidade também é incapaz de decidir por si só a classificação, embora a recepção fora da região em que a obra surgiu ou o autor viveu só possa ser imaginável quando o texto literário atinge certo grau de qualidade. Todavia, o autor adverte que com a bitola do critério qualitativo corre-se o risco, especialmente no caso alemão, de aproximação à imagem rasteira das literaturas raciais ou tribais defendidas, por exemplo, em 1929, por Gottfried FitTBOGEN ${ }^{6}$.

\footnotetext{
${ }^{4}$ Desde 1971, professor e pesquisador no Instituto de Germanística da Universidade de Innsbruck. Especialista nas seguintes áreas: literatura austríaca dos séculos XIX e XX; literatura contemporânea e poesia experimental; literatura alemã do sudeste; literatura tirolesa do norte e do sul; periódicos científicos; análise linguística de textos literários; judaísmo e antissemitismo na literatura; recepção e formação de cânones; língua alemã austríaca.

${ }^{5}$ Todas as citações de textos em alemão serão aqui traduzidas pelo autor.

${ }^{6}$ Gottfried Fittbogen (1878-1941) ficou conhecido na Europa como crítico e historiador da literatura que se colocou a serviço do Nacional-Socialismo, publicando textos com o propósito de exaltar o "universalismo" da literatura e da cultura alemãs, consoante o lema "Deutschland über alles" ("a Alemanha acima de tudo"). Sua obra principal, Was jeder Deutsche vom Grenz- und Auslanddeutschtum wissen ти $\beta$ ( $\mathrm{O}$ que cada alemão deve saber sobre o germanismo dentro e fora da Alemanha), foi publicada em 1924, com apenas 64 páginas e, em 1938, já havia sido ampliada para 280 . O texto a que Scheichl se refere intitula-se Die Dichtung der Auslanddeutschen [A literatura dos alemães no exterior], de 1929.
} 
Arendt, J. C. - Contribuições alemãs para o estudo das literaturas regionais

À valoração estética, Scheichl antepõe critérios sociológicos a fim de definir uma obra ou autor como regional ou suprarregional. Para isso, deve-se perguntar em quais meios o autor publicou, onde seus textos foram editados após a morte, a que público suas obras se dirigem e por quem elas de fato são ou foram lidas. Tal critério ajudaria a distinguir com mais propriedade a literatura regional e a literatura não regional, até porque haveria muita diferença entre um autor publicar na editora Krafft, em Hermannstadt ${ }^{7}$, e na S. Fischer, em Berlim. Com isso, toca-se em questões referentes aos meios de produção e difusão das obras.

Outro argumento relevante diz respeito ao fato de que, muito mais que as editoras regionais, as editoras suprarregionais podem facilitar a difusão de textos literários em forma de resenhas que exercem influência sobre o autor e que não são necessariamente encomendadas pelo editor a críticos apadrinhados. Nesse sentido,

a divulgação em um periódico de grande circulação significa para um autor a confirmação efetiva da sua qualidade e tem uma influência importante na continuidade do seu trabalho de escrita, para além dos conselhos do editor que muitas vezes levam a alterações no texto (SCHEICHL 1993: 36).

Aqui, para fazer coro ao sete-burguense Michael Albert, estudado por Scheichl, é possível inserir um exemplo da literatura regional brasileira, cuja recepção constitui caso digno de nota. Trata-se do escritor Simões LOPES NETO, cujas obras foram inicialmente publicadas pela Livraria Universal de Pelotas, em 1910 (Cancioneiro guasca), 1912 (Contos gauchescos) e 1913 (Lendas do Sul). A editora, fundada em 1887, tinha seu alcance restrito aos públicos municipal e estadual e, do ponto de vista mercadológico, fazia concorrência à Livraria Americana, inaugurada na mesma cidade em 1875. Mesmo estendendo seus negócios até Rio Grande e Porto Alegre, a Livraria Universal sobreviveu apenas até a década de 1920.

A hipótese levantada por Mário Osório MAGALHÃES acerca da escolha do nome da editora é significativa da projeção desejada por seu fundador, Carlos A. Echenique:

\footnotetext{
${ }^{7}$ Herrmannstadt (ou Cibiu), maior cidade de Sete-Burgos (Transilvânia), foi fundada por colonos alemães no século XII. Depois da dissolução do império austro-húngaro, no fim da Primeira Guerra Mundial, integrou-se à Romênia e hoje possui cerca de 150.000 habitantes.
} 
Arendt, J. C. - Contribuições alemãs para o estudo das literaturas regionais

Avanço até a hipótese, diante disso, de que a Livraria Universal escolheu o próprio nome com o objetivo de contrapor-se à concorrente. Ou seja: pretendia demonstrar, de forma implícita, por meio da razão social, que, no âmbito da cultura, sua abrangência era maior; figurativamente, queria dizer que era geral, universal, não se limitava, como a outra, às configurações de um continente. (MAGALHÃES 2003)

Mesmo que não seja possível, neste momento, confirmar a hipótese de Magalhães, os nomes das duas casas editoras são testemunhas de um momento histórico e literário em que tanto a americanidade quanto a universalidade impõem-se como bandeira e paradigma. Basta que se folheiem exemplares de poesia e prosa românticos, bem como de ensaios críticos de meados do século XIX, para que se confirme a informação: o universalismo pleiteado para a nova América concorre nitidamente com o alcance até então projetado pela velha Europa.

Simões Lopes estreia, portanto, sob a chancela da Universal, mas suas obras permanecem por algumas décadas praticamente restritas ao âmbito regional de circulação, e nem mesmo o volume de Contos gauchescos e lendas do Sul, publicado pela Editora Globo de Porto Alegre em 1926, sendo o autor ainda jovem e sem projeção suprarregional, foi capaz de impulsionar o seu transbordo. Somente em 1949, inaugurando a sugestiva Coleção Província, a Globo mais uma vez reproduz os contos e lendas, agora numa edição crítica com prefácio de Augusto Meyer, glossário de Aurélio Buarque de Hollanda e estudo biográfico de Carlos Reverbel, a qual tem reimpressões em 1950, 1951, 1953, 1957, 1961, 1965 e 1973. A inserção do autor no circuito suprarregional ganha ainda mais força a partir da década de 1960, com a sua publicação por outras editoras, como a Agir, do Rio de Janeiro, sob a direção de Alceu Amoroso Lima, a ponto de atualmente figurar nos mais diferentes formatos e nas mais diversas casas editoriais. Paulatinamente, também, suas obras mereceram o exame dos mais importantes estudiosos da literatura brasileira, desde Augusto Meyer, Flávio Loureiro Chaves e Ligia Chiappini até Antonio Candido 8.

Não se trata de supervalorizar a bandeira da qualidade literária, como sugere Scheichl, para explicar o transbordo de Simões Lopes da fronteira regional, porque o

\footnotetext{
${ }^{8}$ Respectiva e cronologicamente, consultar a pesquisa desenvolvida por: MEYER, Augusto. Prosa dos pagos. São Paulo, Martins, 1943; CÂNDIDO, Antonio. "A literatura e a formação do homem". Revista Ciência e Cultura. São Paulo, v.24, n.9, set. 1972; CHAVES, Flávio Loureiro. Simões Lopes Neto: regionalismo \& literatura. Porto Alegre, Mercado Aberto, 1982; CHIAPPINI, Lígia. No Entretanto dos Tempos. Literatura e História em João Simões Lopes Neto. São Paulo: Martins Fontes, 1988.
} 
Arendt, J. C. - Contribuições alemãs para o estudo das literaturas regionais

enfoque proposto privilegia aspectos de natureza editorial, de circulação e recepção das obras regionais. Se a produção do "escritor municipal”, como foi chamado por Carlos REVERBEL (1981), encontrou postumamente canais editoriais, críticos e de recepção para ultrapassar a região em que viveu, publicou e que representou, isso já constitui um indício não de seu caráter universal, mas do valor e do significado atribuídos à sua obra ao longo do tempo.

Além disso, vários estudos que explicitaram o comprometimento de Contos gauchescos e lendas do Sul com a ideologia do regionalismo gauchesco paradoxalmente também isentaram as obras com a atribuição de um caráter universal. Sem entrar no mérito da discussão acerca das disputas interregionais, muitas vezes travadas de forma dissimulada nos meios acadêmico, literário e intelectual, convém dizer, finalmente, com a ajuda de Janet WOLFF (1982: 134), que "as ideias e crenças propostas como isentas de valor e não partidárias são apenas aquelas que assumiram o disfarce da universalidade, vendo como naturais fatos e relações que são, na verdade, historicamente específicos". Terá sido nosso desejo de isenção que desideologizou um autor que conclamou "a raça que se está formando a aquilatar, amar e glorificar os lugares e os homens dos nossos tempos heróicos, pela integração da pátria comum"? (LOPES NETO 1988: 19)

Scheichl afirma também, em seu estudo, que a ruptura intencional de autores com o âmbito regional, que por si só denotaria o transbordo da literatura regional, não significa necessariamente o ingresso em um sistema literário mais amplo. Mas a tentativa de renovação temática e de distanciamento das tradições regionais constitui uma tomada de consciência para se distinguir daqueles escritores inseridos no mesmo contexto. $\mathrm{O}$ autor vê como importante para esse transbordo a procura por editoras fora da região do escritor, onde a recepção poderá ter características diferentes, independentemente da cor regional ou da temática. Além disso, é possível que um escritor ganhe projeção suprarregional quando, mesmo escrevendo para um público regional, formula experiências coletivas que ainda não encontraram lugar em nenhum outro autor ou nem podem ser exprimidas em qualquer outra literatura escrita.

Por último, do ponto de vista do transbordo post mortem de autores da literatura regional, Scheichl acredita que ele poderá ocorrer em casos de uma recepção mais tardia, de polêmicas literárias ou quando se procura encontrar um lugar de destaque para o escritor na literatura nacional. Em sentido contrário, também pode um escritor 
Arendt, J. C. - Contribuições alemãs para o estudo das literaturas regionais

suprarregional, após sua morte, voltar a circular apenas em âmbito regional, perdendo, portanto, o lugar que antes ocupava num sistema literário mais amplo.

\section{Literatura regional ou literatura em uma região?}

Na mesma linha de pesquisa de Scheichl, estão os estudos de Jens STÜBEN, da Universidade de Oldenburg. ${ }^{9}$ Em seu texto "Literatura regional e literatura em uma região" ('Regionale Literatur' und 'Literatur in der Region') - publicado em 2002 na obra A regionalidade como categoria de estudos das ciências literárias e linguísticas, organizada pelo Instituto de Filologia Germânica da Universidade de Opolski, na Polônia, num projeto que reuniu editores de Frankfurt/M., Berlim, Berna, Bruxelas, Nova Iorque, Oxford e Viena -, o autor propõe uma distinção metodológica e conceitual entre literatura em uma região, literatura de uma região ou oriunda de uma região, literatura localizada na região, literatura regional, literatura regionalista, literatura provinciana e literatura pátria [Heimatliteratur].

O pesquisador alemão parte da afirmação de que a existência de uma consciência regional - fruto do intercâmbio entre localidade geográfica e significação cultural -, à medida que influencia a temática das produções literárias e contribui para a recepção, é condição sine qua non para o desenvolvimento de pesquisas voltadas a uma história literária regional. Em sua opinião, porque os escritores e os leitores desde sempre se movem por espaços de significação e de experiência, as regiões e seus caracteres terminam por ser, de alguma forma, representados na literatura ${ }^{\mathbf{1 0}}$. Essas

\footnotetext{
${ }^{9}$ Professor, desde 1992, no Instituto de Germanística da Universidade de Oldenburg. Seu foco de pesquisa concentra-se em: nova literatura alemã (séc. XIX e XX); iconologia literária; literatura prussiana oriental e ocidental; literatura silesiana e da Áustria antiga; literatura e topografia.

${ }^{10}$ A propósito, ver o capítulo "O regional e o universal", em que Pozenato, em 1974, pioneiramente no Brasil, formula o conceito de regionalidade e estabelece a seguinte proposição: "A regionalidade está na representação de um universo regional, feita segundo um modo de ser regional. De uma maneira simplificada se poderá dizer que a regionalidade repousa sobre uma temática e um modus faciendi regionais, entendido este último não apenas como a utilização de uma técnica peculiar, mas como toda a maneira de se posicionar frente ao mundo, aquilo que se chama comumente 'estilo de vida'. E que engloba tanto a praxis como o ethos que a preside" (1974: 20). O autor retoma a discussão em 2001, quando estabelece uma distinção conceitual entre região, regionalismo, regionalização e regionalidade.
} 
Arendt, J. C. - Contribuições alemãs para o estudo das literaturas regionais

representações, por sua vez, que se formam na mente dos leitores e continuam produzindo efeitos, contribuem para erigir e estilizar a imagem das respectivas regiões. É nesse sentido que a literarização da região e a regionalização de sua literatura e também a regionalização da região - esta última enquanto acomodação da região a uma imagem literária da literatura regionalizada - entrelaçam-se continuamente.

Stüben ressalta que o crescente interesse dos pesquisadores alemães pela região deve-se, além do exposto acima, ao fato de muitos autores, no século XX, terem deixado suas regiões de origem premidos por acontecimentos que marcaram a história europeia. São escritores exilados, desalojados, fugitivos e emigrados:

Todos eles estavam e estão em grande parte cunhados por suas regiões de origem, deram e dão respostas literárias às próprias perguntas sobre suas identidades regionais, que eles relacionam com suas identidades nacionais. Eles escrevem geralmente sob o impulso da perda de suas antigas pátrias e pela necessidade de desenvolverem novas relações regionais. (STÜBEN 2002: 53)

Desse modo, poetas, romancistas e dramaturgos de língua alemã, oriundos da Europa oriental, não são apenas testemunhas do tempo, mas também testemunhas do espaço. Seus textos resultam tanto de experiências regionais diretas, como englobam ainda o testemunho e a memória de terceiros. Ao mesmo tempo, porém, naquelas obras que não se ambientam na região de origem dos seus autores são igualmente perceptíveis traços de socialização, ou seja, de educação, Bildung [formação] e horizonte de experiências que são influenciados pelos biótipos locais, pela cultura regional e pelas tradições.

Não há dúvidas de que no Brasil ainda está por se fazer um estudo detalhado acerca das literaturas de migração, imigração e de exílio e suas implicações nos espaços regionais de origem ou de adoção. Se, por exemplo, José de Alencar, morando no Rio de Janeiro, ambientou algumas de suas obras na terra natal, o Ceará; se Ferreira Gullar, exilado no Chile, escreveu o "Poema sujo", que se ambienta em São Luis do Maranhão, cidade onde nasceu; se Guimarães Rosa, em franca perambulação pelo mundo, como

Igualmente, consulte-se o ensaio de Ligia Chiappini, "Do beco ao belo: dez teses sobre o regionalismo na literatura", em que a autora faz a seguinte afirmação: "Na obra regionalista, a região existe como regionalidade, e esta é o resultado da determinação como região ou província de um espaço ao mesmo tempo vivido e subjetivo, a região rural internalizada à ficção, momento estrutural do texto literário, mais do que um espaço exterior a ele". Assim, "a função da crítica diante das obras que se enquadram na tendência regionalista é, por isso, indagar da função que a regionalidade exerce nelas” (1999: 158). 
Arendt, J. C. - Contribuições alemãs para o estudo das literaturas regionais

diplomata, ambientou suas narrativas em Minas Gerais, o lugar onde nasceu; se Simões Lopes Neto, excetuando-se uma curta estadia de estudos no Rio de Janeiro durante a adolescência, nunca mais se distanciou da região representada em sua obra; e se José Clemente Pozenato, descendente de imigrantes italianos, ambienta seus romances e novelas na região da imigração italiana no Rio Grande do Sul - então (e a lista poderia se estender por algumas páginas, incluindo também escritores de alcance apenas municipal ou regional, os rotulados não universais), há razões suficientes para se pensar melhor, também no Brasil, as questões que envolvem autores, obras e regiões. E um estudo dessa natureza poderia ter como base o critério da regionalidade, que "abarca tudo aquilo que traz a marca do regional, mesmo sem regionalismo" (POZENATO 1974: 19).

Atravessando uma longa lista de escritores do século XX, desde Günther Grass até Paul Celan, Stüben desemboca na questão central do seu artigo: "Existem realmente paisagens literárias, e de que modo se definem regiões literárias, cujas fronteiras não necessitam coincidir com fronteiras políticas?” (STÜBEN 2002: 56). Na opinião do autor, regiões literárias podem ser determinadas e delimitadas entre si ora como áreas diferenciadas pelo trabalho de criação dos autores, ora como espaços de experiência que orientam temática e objetualmente os autores, ora como zonas de interação entre autores e meios de divulgação, ora como áreas de efeito dos textos literários. Daí emergiriam dois aspectos centrais para uma história literária das regiões, tomando a inter-relação entre literatura e espaço: primeiro, o espaço como motivação dos autores para a escrita e sua consequente vinculação temática; segundo, o lugar em que os autores encontram de forma massiva o seu público. Em razão disso, Stüben, apoiado em reflexões de Norbert Mecklenburg, julga possível indagar "como a literatura se desenvolveu em uma região, como a região atua sobre temas, formas, produção e recepção literários e como a literatura pode, em sentido contrário, atuar sobre a região ou, pelo menos, sobre a imagem da região" (STÜBEN 2002: 57).

Para chegar a isso, o autor propõe antes uma clarificação de conceitos capaz de tornar possível o mapeamento das literaturas ou das obras literárias conforme as diferentes expressões de suas regionalidades: 
Arendt, J. C. - Contribuições alemãs para o estudo das literaturas regionais

A pesquisa empírica pela literatura em uma região é independente das questões sobre a origem dos autores, o lugar de publicação dos textos, o tema ou o gênero, mas centra-se na existência da literatura como um trabalho de recepção (por exemplo, a literatura na Alta Silésia). Essa abordagem deve ser complementada com a pergunta sobre a literatura oriunda [aus] de uma região, ou seja, a literatura originária de uma região (por exemplo, a literatura $d a$ Alta Silésia ou a literatura alto-silesiana), bem como a pergunta pela literatura sobre uma região (por exemplo, a Alta Silésia como tema literário), já que somente a interação destes três fatores - a recepção, a produção e a temática constitui uma paisagem literária (STÜBEN 2002: 57).

Como "literatura regional" poderia ser denominada aquela literatura que se distancia de centros culturais suprarregionais e se encontra em relativo isolamento das outras regiões. Em outros termos, o conceito de literatura regional é reservado por Stüben para o âmbito da escritura literária restrita à região. Já as obras cujos pressupostos e conteúdos se relacionam claramente com uma região geográfica concreta e dela são inseparáveis podem ser inseridas na literatura localizada regionalmente. Na literatura regionalista, por sua vez, estão aquelas obras que promovem a cultura da região como programa e paradigma, que se distinguem de outros espaços ou se defendem em relação a um centro. Por fim, se uma literatura regional reflete uma província e relações provinciais, bem como a variedade de problemas da Heimat (muitas vezes devido a um influxo emocional), ela não precisa ser necessariamente identificada como literatura $d a$ província ou literatura da Heimat, porque estes termos referem-se à literatura com um distinto colorido local que enfatiza nostalgicamente seus valores contra a infiltração estrangeira, sendo altamente idealizada e tendenciosa.

Deve ficar claro, a esta altura das reflexões, que não se devem utilizar os critérios diferenciadores apresentados pelo autor para desenvolver uma história da literatura regional meramente classificatória das obras. Como já se indicou anteriormente, a interação entre recepção, produção e temática deverá nortear os estudos dessa natureza, porque, dependendo do tipo e do nível das relações de regionalidade de uma obra, ela poderá receber significados diferenciados e diferenciadores. Da mesma forma, a conjugação dos fatores produtivos, de recepção e temáticos contribui para o delineamento das paisagens literárias, dentro das quais se perfila todo tipo de obra, desde a mais trivial até a mais complexa, no que tange às relações de regionalidade.

Ampliando a perspectiva de Scheichl, Stüben também indaga acerca dos fatores socioculturais regionais que atuam sobre a produção e a recepção das obras, acerca das 
Arendt, J. C. - Contribuições alemãs para o estudo das literaturas regionais

instituições da vida literária em uma região, bem como sobre a existência, em especial, de condições de leitura e de publicidade literária. Para dar conta desse questionamento, o autor elenca uma série de tópicos de investigação que, dependendo da região em estudo, podem ter características e pesos diferentes. Destacamos os seguintes:

- Condições políticas e históricas;

- Relações econômicas e desenvolvimento demográfico (agricultura, industrialização, urbanização);

- Comunidades religiosas;

- Circunstâncias étnicas, histórico-populacionais, geográficoculturais, socioculturais e histórico-mentais, bem como questões sobre a autoconsciência coletiva, em especial:

- Significado dos centros culturais dentro e fora da região, canais de comunicação, relações culturais;

- Situação linguística (linguagem escrita e recursos dialetais, áreas de uso da linguagem, processos de troca entre os dialetos e línguas vizinhas, bilinguismo e multilinguismo);

- Consciências regional, nacional, identidade étnica e cultural (fronteiras, existência de minorias, multiculturalismo), e seus reflexos na literatura;

- Tradições culturais, convenções, usos e costumes;

- Estruturas de pensamento, padrões de (auto)interpretação, atitudes, valores, padrões de comportamento, ideologias;

- Educação;

- Escolas, universidades (como instituições de formação dos autores e seu público, como locais de pesquisa científica e espiritual);

- O ensino de línguas, a educação literária;

- Vias e meios de difusão da literatura (vida literária), instituições culturais, imprensa;

- Jornais, revistas, calendários, almanaques;

- Editoras e livrarias;

- Bibliotecas para pesquisa e empréstimo;

- Grêmios literários, clubes culturais, grupos de leitura, salões, performances de poesia; 
Arendt, J. C. - Contribuições alemãs para o estudo das literaturas regionais

- Crítica literária;

- Política cultural de Estado, regional e local;

- Processos culturais (intelectuais e literários) de transferência, relações transversais internas entre diferentes línguas e literaturas, bem como fora das fronteiras regionais e nacionais, efeitos sobre os escritores e público, em especial:

- Recepção da literatura em outras regiões (vizinhas), a simultaneidade ou não simultaneidade de tendências literárias em diversas regiões;

- A recepção da literatura estrangeira no original ou em tradução;

- Tradução para outras línguas que possibilitem a recepção dentro e fora da região;

- Influências sobre a literatura das regiões vizinhas, sobre a literatura nacional em geral e literaturas de língua estrangeira (Cf. STÜBEN 2002: 62-63).

Os diferentes fatores econômicos, históricos, políticos, geográficos, religiosos e sociais - culturais, enfim -, atuam direta e indiretamente sobre a produção e a recepção da literatura nos níveis regional e suprarregional. Daí emerge não só a possibilidade de se (dar a) conhecer em seus múltiplos aspectos o sistema literário regional, mas também o delineamento do próprio conceito de região que haverá de interessar aos estudiosos da literatura. Mais do que isso, traz à luz a diversidade das chamadas paisagens literárias, que constituem o território da literatura, da menor escala até a mais ampla. Se esse procedimento é eminentemente empírico, porque investiga os múltiplos fatores responsáveis pelo surgimento e desenvolvimento da literatura em âmbito regional e desemboca na configuração de paisagens literárias, um outro ângulo de estudos também é possível: o da representação literária do universo de valores regionais e supraregionais, ou seja, a discussão das relações de regionalidade incorporadas às obras e o seu possível efeito sobre a imagem da própria região.

Na sequência de sua reflexão, Stüben ainda apresenta critérios relativos às obras que poderiam ser inseridas numa história literária de contornos regionais tendo como referência um conceito bastante amplo de literatura, das quais destacamos as seguintes: 
Arendt, J. C. - Contribuições alemãs para o estudo das literaturas regionais

- aquelas surgidas na respectiva região;

- aquelas em que se entrelaça o discurso regional e se revelam as relações intertextuais com implicações regionais;

- aquelas que resultam da experiência direta do autor sobre paisagens, lugares e pessoas de uma região;

- aquelas que representam a região tendo-a como referência temática e de fundo;

- aquelas que foram escritas principalmente para o público de uma região;

- aquelas que foram publicadas em uma editora ou em um órgão de imprensa da região;

- aquelas que na região (com o apoio da crítica, do público literário e de outros autores) se expandiram e tiveram algum efeito principalmente por causa de seus estreitos laços temáticos;

- aquelas escritas por autores que viveram na região e que são inspiradas pela paisagem, sua gente e cultura;

- aquelas que, em especial, estão altamente impregnadas de mitificados lugares de memória, os quais se ancoram na memória da posteridade ou que devem ser preservados na consciência das gerações seguintes - sejam monumentos culturais, cidades, fatos de personalidades ou paisagens, sejam lugares de sofrimento, como os campos de batalha, de concentração e de extermínio (Auschwitz), rotas de fuga e expulsão. (Cf. STÜBEN 2002: 67-68)

Com base nesse rol de possibilidades, ocorre de imediato a lembrança de que a literatura regional é pródiga em criar lugares de memória, podendo estes se relacionar à representação não só de monumentos, prédios ou locais históricos, mas, num sentido amplo, também de pessoas, eventos, textos, ideias, rituais, canções, instituições. É necessário pensar, ainda, que esses lugares funcionam, para determinados grupos sociais e através das gerações, como pontos de cristalização da memória e da identidade regional e suprarregional. Mais uma vez, poderíamos remeter aqui a Simões Lopes Neto e abrir as páginas de seus Contos gauchescos para ilustrar essa questão, já que avultam referências toponímicas e antroponímicas relacionadas aos eventos históricos que se 
Arendt, J. C. - Contribuições alemãs para o estudo das literaturas regionais

desenvolveram na região por ele representada. Mas como não é esse o propósito do trabalho, limitamo-nos apenas à lembrança de sua obra e à referência ao fato de que os lugares de memória podem ser estudados tendo como objeto as literaturas regionais - e também elas mesmas enquanto lugares de memória privilegiados.

\section{Literatura regional e conceito de espaço}

Outro estudo que merece a atenção quanto à delimitação de aspectos conceituais e metodológicos no campo dos estudos literários regionais intitula-se "Literatura na região e conceito de espaço" [Literatur in der Region und Raumbegriff], publicado por Jochen GRYWATSCH ${ }^{\mathbf{1 1}}$, em 2008, na obra Tradição cultural: burguesia, literatura e vida comunitária na Renânia 1830-1945. O autor inicia sua reflexão estabelecendo uma relação entre as categorias tempo, como paradigma dominante para a descrição e compreensão do mundo desenvolvido pelo Iluminismo, e a categoria espaço, que se opôs àquela apenas recentemente em função do grande descrédito suscitado pela ideologia nazista, que utilizou os termos espaço, região e pátria no sentido de um pensamento nacionalista e racista.

Assim, em oposição à ênfase da modernidade no tempo, a chamada pósmodernidade teria definido uma nova consciência orientada para o espaço, principalmente depois de o teórico americano Frederic Jameson ter defendido, na década de 1980, o slogan "Always spatialize!“. O espaço gozaria, então, desde o final do século XX, de uma nova ou renovada matriz de percepção e descrição. Segundo GRYWATSCH,

O espacial, o topográfico, a referência a espaços e lugares, regiões e paisagens, ganharam a atenção considerável não só de uma variedade de disciplinas, como as ciências culturais, geográficas, literárias e históricas, mas também do público em geral. As categorias espaço e espacialidade estão em foco por toda parte (2008: 85).

\footnotetext{
${ }^{11}$ Pesquisador da Comissão de Literatura da Vestefália, que integra a Associação Regional de VestefáliaLippe, na cidade de Münster. Especialista em Germanística, Anglicística, Americanística e Romanística. Pesquisa atualmente a obra da escritora Annette von Droste-Hülshoff, literatura regional, literatura na Vestefália, literatura e arquivo.
} 
Arendt, J. C. - Contribuições alemãs para o estudo das literaturas regionais

Em especial nos estudos acadêmicos alemães, o autor informa que Sigrid Weigel proclamou, em 2002, o topographical turn para os Estudos Culturais, enquanto o historiador Karl Schlögel, em 2003, na esteira do cientista social Edward Soja, postulou o spatial turn; e mais recentemente, em 2005, o estudioso dos meios de comunicação, Stephan Guenzel, formulou o topological turn. A diferenciação entre os três turns deve ser feita conforme o enfoque metodológico de cada um deles: o spatial turn detém-se na tematização geral do conceito de espaço; o topographical turn focaliza as formas de representação do espaço; e o topological turn enfoca a descrição de estruturas, relações e posições espaciais.

Para o autor, no entanto, o atual discurso sobre o espaço encontra-se assentado num claro contexto de ambiguidade, porque, ao mesmo tempo em que o pósmodernismo lhe dá ênfase particular, cada vez mais sua percepção é marcada por fenômenos de deslocamento e desespacialização, provocados pelas conexões de comunicação global que, ao promoverem a world wide web, fomentam um sensível desenraizamento. De qualquer modo, segundo Grywatsch, a globalização torna a perspectiva espacial necessária e indispensável, marginalizando as categorias "evolução" e "progresso" e acentuando a simultaneidade, a convivência e os intercâmbios.

Depois de buscar informações históricas sobre a relação entre literatura e espaço no âmbito alemão anterior ao pós-modernismo, o autor volta-se para a definição de conceitos acerca da literatura regional. Nesse sentido, afirma que as pesquisas atuais sobre literatura regional têm em comum o fato de elas se afastarem de uma concepção estreita que buscaria apenas as características culturais de uma região, porque uma orientação entendida dessa maneira cairia rapidamente na suspeita de um comprometimento com a cultura local (o Heimattümelei, no caso alemão). Isso mostra que os conceitos de região e regionalidade, conforme Grywatsch, ainda não estão suficientemente definidos, de modo que o uso do termo literatura regional ainda é entendido equivocamente como um mero sinônimo de literatura pátria (Heimatliteratur). 
Arendt, J. C. - Contribuições alemãs para o estudo das literaturas regionais

Hoje, segundo o autor, a pesquisa sobre a literatura regional deve se comprometer antes com a complexidade e a interação de elementos de ordem geográfica, linguística e sociocultural de uma região. O objetivo não é o de focalizar uma suposta regionalidade dos textos, mas estudar, em sua especificidade histórica e dinâmica, o conjunto de aspectos que tornam possível a vida literária em um contexto espacial regional. Daí que o termo mais adequado para definir este tipo de investigação seria literatura $n a$ região, que é preferível à expressão literatura regional, porque relativiza a ideia de unidade que subjaz a esta última. Tomando como base resultados de pesquisa publicados pela Comissão de Literatura da Vestefália, Grywatsch afirma que "literatura em uma região [...] descreve a complexidade do acontecimento literário definível espacialmente - em um âmbito subnacional, também abaixo da (fora) ou além da unidade administrativa dos estados, em um dado momento histórico" (2008: 90).

Juntamente com esse enfoque, emerge a categoria da transregionalidade, a partir da qual se torna possível investigar uma complexa rede de referências que contribuem para determinar os processos de intercâmbio entre as regiões. Já o conceito de região, para o autor, não deve significar uma realidade natural em um espaço específico, mas um modelo de referência com potencial de identificação, construído dentro de um processo cultural. E, por último, no que se refere à relação entre região e espaço, Grywatsch propõe que, se a atual ênfase no regional coincide com a virada pós-moderna em direção ao espaço, então seria oportuno utilizar e tornar fecundos, na pesquisa sobre literatura regional, os métodos, práticas e pontos de vista dos estudos sobre o espaço. Da mesma forma, essas investigações poderiam ser úteis no campo das literaturas de exílio e de diáspora, porque o conceito de região traz em si a ideia de isolamento e coloca em curso processos de identificação que se comprometem com estruturas de poder na maioria das sociedades.

\section{Conclusões}

Da discussão efetuada até aqui, depreendem-se algumas conclusões que formulamos da seguinte maneira: 
Arendt, J. C. - Contribuições alemãs para o estudo das literaturas regionais

1. Editoras e periódicos, especializados ou não, cumprem um papel determinante para o transbordo da literatura regional. Daí não se poder desprezá-los quando se trata de estudar qualquer sistema de comunicação literária, até porque na história da literatura brasileira sobejam casos em que os autores encontram, de início, somente em sua região condições adequadas à publicação e recepção dos textos. Geralmente, os primeiros ensaios de escrita vêm a público em editoras ou jornais de circulação limitada ou são premiados em certames promovidos por instituições de influência regional. Tanto isso é verdade que até hoje pesquisadores dão-se ao trabalho de vasculhar acervos de cidadezinhas do interior brasileiro à cata de textos inéditos de escritores ou de críticas pioneiras. Simões Lopes, nosso exemplo didático, publicou muitos dos textos que depois comporiam Contos gauchescos e Lendas do Sul em jornais de Pelotas e Rio Grande (quantos textos simonianos ainda aguardam ser descobertos, especialmente em razão do abuso de pseudônimos usados para manter em sigilo sua identidade perante o grupo regional?). Em suma, pode-se perguntar: qual autor, suprarregional de preferência, não viveu, em algum momento da sua vida, a experiência da circulação estritamente regional de seus textos, participou de grupos literários locais, escreveu para os leitores com que se relacionava cotidianamente e não buscou primeiro aí o reconhecimento para seu trabalho?

2. O público da literatura regional constitui-se da mesma forma que o público da literatura suprarregional: por intermédio da atuação de editoras, periódicos, eventos e instituições locais. Os leitores, motivados não necessariamente pela carência de autores, que aí podem aportar em razão do transbordo de outras literaturas regionais, mas, às vezes, por um sentimento de pertença às coisas locais e pela satisfação de verem seu universo de referências cotidianas representado pela linguagem literária, defendem e prestigiam seus escritores. E nesse sistema de recepção organizada pode se esconder até o desejo de ver sua região crescer em importância e transbordar para outras regiões, atribuindo-se aos escritores, desse modo, o ofício de porta-vozes de seus valores. Também o regionalismo econômico e político que se imiscui no público leitor é propenso 
Arendt, J. C. - Contribuições alemãs para o estudo das literaturas regionais

a encontrar em seus escritores, não necessariamente só nos regionalistas, um instrumento eficaz de controle e ação tanto sobre a própria região quanto sobre as regiões vizinhas. Sem aprofundar a questão, é prudente levar em conta que a literatura regional está tão sujeita à manipulação ideológica quanto as literaturas regionalista e suprarregional.

3. Criticar um escritor por escrever para um público regionalizado, independentemente de sua falta de isenção ideológica para com a cor regional, pode condenar determinados grupos ao silêncio e ao desaparecimento. Existem particularidades que apenas os escritores regionais são capazes de captar e expressar, e que muitas vezes se expressam por meio de dialetos muito restritos. ${ }^{12}$ Esse tipo de literatura tenderá a ser consumido por aquele grupo que de fato experiencia diretamente tanto a linguagem quanto os seus significados. Somente quem fez/faz uso de um dialeto será capaz de dimensionar com maior clareza essa questão, pois determinados objetos e vivências, quando traduzidos para um idioma dominante ou oficial, perdem completamente os sentidos da experiência e a capacidade de comunicação e de adesão daquele público. O registro literário das particularidades regionais contribuirá, em suma, para a manutenção não da diferenciação, mas da diversidade cultural geográfica.

4. O conjunto de elementos passíveis de estudo na literatura regional deve avançar até aspectos históricos e sociais, desviando da tradicional polarização entre regional e universal. Isso significa dizer que, mais do que emitir juízos valorativos, é o contexto de produção e recepção das obras literárias que precisa ser investigado, para se chegar à dinâmica literária em escala reduzida, ou às paisagens literárias. Não se trata, portanto, de se debruçar apenas sobre o critério da qualidade literária para explicar o transbordo de autores regionais,

\footnotetext{
${ }^{12}$ Ver, por exemplo, a seguinte obra, considerada hoje um verdadeiro best-seller entre usuários do dialeto vêneto: BERNARDI, Aquiles; STAWINSKY, Alberto Victor. Nanetto Pipetta: nassuo in Itália e vegnudo in Mérica per catare la cuccagna. 5.ed. Porto Alegre, EST, 1976.
} 
Arendt, J. C. - Contribuições alemãs para o estudo das literaturas regionais

porém pesquisar de forma detalhada as variáveis do ambiente cultural e intelectual em que se formam e se movem os escritores e o público leitor.

5. Aproximar os estudos sobre a literatura regional das teorias pós-modernas sobre o espaço significa, por exemplo, estreitar os laços com a Geografia Cultural, não só porque a região é, por tradição, uma categoria de estudos e um conceito-chave dessa disciplina, mas também porque os geógrafos culturais se debruçam hoje sobre os significados dos fatos visíveis, derivando para a noção de construção cultural das paisagens, as quais são, em última instância, construções simbólicas que variam no tempo e no espaço. Conforme Claval, “a vida dos grupos humanos e suas atividades jamais são puramente materiais. São a expressão de processos cognitivos, de atividades mentais, de troca de informação e de ideias. As relações dos homens com o meio ambiente e com o espaço têm uma dimensão psicológica e sociopsicológica. Nascem das sensações que as pessoas experimentam e das percepções a elas ligadas" (2001: 39).

6. A utilização da categoria universal para medir qualitativamente a literatura regional brasileira deve ser, antes de tudo, investigada com profundidade quanto às suas implicações ideológicas ao longo do tempo. Suas raízes encontram-se na segunda metade do século XIX e, inicialmente, vinculam-se a um movimento de promoção e equiparação da cultura brasileira à cultura europeia. Depois, inscreve-se nas lutas simbólicas entre as diversas regiões e tem, no meio acadêmico, seu espaço privilegiado. Assim, em vez de se dar continuidade a seu uso, seria oportuno buscar as razões de seu uso. Como assegura Renato ORTIZ, "o universal termina onde começam a cultura e a língua, ou seja, no momento em que se determina um substrato comum a todos, um elemento específico os distancia: a cultura” (2007: 8). 
Arendt, J. C. - Contribuições alemãs para o estudo das literaturas regionais

\section{Referências bibliográficas}

Assis, Machado de. Critica Litteraria. Rio de Janeiro, Jackson Editores, 1942.

ARENDT, João Claudio. Histórias de um Bruxo Velho: ensaios sobre Simões Lopes Neto. Caxias do Sul, Educs, 2004.

BERNARDI, Aquiles; STAWINSKI, Alberto Victor. Nanetto Pipetta: nassuo in Itália e vegnudo in Mérica per catare la cuccagna. $5^{a}$ edição. Porto Alegre, EST, 1976.

BosI, Alfredo. História concisa da literatura brasileira. [1970] 37ª edição. São Paulo, Cultrix, 1970.

CANDIDO, Antonio. Sagarana. [1947] In: CouTINHO, Eduardo. Guimarães Rosa. $2^{a}$ edição. Rio de Janeiro, Civilização Brasileira, 1991, p.243-247.

A literatura e a formação do homem. Revista Ciência e Cultura. São Paulo, v.24, n.9, set. 1972.

ChAVES, Flávio Loureiro. Simões Lopes Neto: regionalismo \& literatura. Porto Alegre, Mercado Aberto, 1982.

ChiAPPINI, Lígia. Do beco ao belo: dez teses sobre o regionalismo na literatura. Estudos históricos, Rio de Janeiro, vol.8, n.15, 1995, p.153-159.

No Entretanto dos Tempos. Literatura e História em João Simões Lopes Neto. São Paulo: Martins Fontes, 1988.

Claval, Paul. O papel da nova geografia cultural na compreensão da ação humana. In: ROSENDHAL, Zeny; CORRÊA, Roberto Lobato. Matrizes da geografia cultural. Rio de Janeiro, Eduerj, 2001.

Coutinho, Afrânio. A literatura no Brasil. Vol.4, 6ª edição. São Paulo, Global, 2001.

GRYWATSCH, Jochen. Literatur in der Region und Raumbegriff. In: ILBRIG, Cornelia, KORTLÄNDER, Bernd, STAHL, Enno (Orgs.). Kulturelle Überlieferung. Bürgertum, Literatur und Vereinswesen im Rheinland 1830-1945. Düsseldorf, Heinrich-HeineInstitut, 2008, p. 84-95.

JOACHIMSTHALER, Jürgen. A literarização da região e a regionalização da literatura. Antares (Letras e Humanidades), Caxias do Sul, n², jul/dez 2009.

LOPES NETO, João Simões. Contos gauchescos [1912]. Edição comentada por Aldyr Garcia Schlee. Porto Alegre, Novo Século, 2000.

Magalhães, Mario Osório. Americana e Universal. Diário Popular, Pelotas, 31/08/2003.

MeYer, Augusto. Prosa dos pagos. São Paulo, Martins, 1943.

ORTIZ, Renato. Anotações sobre o universal e a diversidade. Revista Brasileira de Educação, Rio de Janeiro, vol.12, n.34, jan./abr. 2007.

Pozenato, José Clemente. O regional e o universal na literatura gaúcha. Porto Alegre, Movimento, 1974.

Algumas considerações sobre região e regionalidade. In: ZILLES, Urbano. Filosofia: diálogo de horizontes. Porto Alegre, EDIPUCRS; Caxias do Sul, EDUCS, 2001.

Reverbel, Carlos. Um Capitão da Guarda Nacional: vida e obra de J. Simões Lopes Neto. Caxias do Sul, UCS; Porto Alegre, Martins Livreiro, 1981. 
Arendt, J. C. - Contribuições alemãs para o estudo das literaturas regionais

SANTOS, Rafael José dos. Relatos de regionalidade: tessituras da cultura. Antares (Letras e Humanidades), Caxias do Sul, ano 1, n. 2, jul/dez 2009.

SCHEICHL, Sigurd Paul. Der Austritt aus der Regionalliteratur. In: TONTSCH, Brigitte; SCHWOB, Anton (Orgs.). Die siebenbürgisch-deutsche Literatur als Beispiel einer Regionalliteratur. Köln, Siebenbürgisches Archiv, 1993, p. 33-49.

STÜBEN, Jens. 'Regionale Literatur' und 'Literatur in der Region'. Zum Gegenstandsbereich einer Geschichte der deutschen Literatur in den Kulturlandschaften Ostmitteleuropas. In: JOACHIMSTHALER, Jürgen (Org.). Regionalität als Kategorie der Sprach- und Literaturwissenschaft. Frankfurt, Berlim, Berna, Bruxelas, Nova Iorque, Oxford e Viena. 2002, p. 51-75.

Recebido em 10/10/2010

Aprovado em 28/02/2011 